$\xi \mathrm{p}$

\title{
Naphthoquinone impairs reproductive functions in plasmodium berghei berghei-infected male swiss mice
}

\author{
Nkereuwem Sunday Etukudoh ${ }^{1}$, Opeyemi Oreofe Akindele ${ }^{2 *}$, Olufadekemi Tolulope Kunle-Alabi ${ }^{2}$, \\ Adeyombo Folashade Bolarinwa ${ }^{2}$ \\ ${ }^{1}$ Federal School of Medical Laboratory Science, Jos, Nigeria \\ ${ }^{2}$ Department of Physiology, College of Medicine, University of Ibadan, Ibadan, Nigeria \\ *Corresponding author E-mail: opeyemiakindele@gmail.com
}

\begin{abstract}
Background: Various antimalarial drugs adversely affect male reproductive functions. Naphtoquinones, a class of antimalarial drugs have been shown to effectively combat malaria parasites. However, the effects of naphtoquinone on reproductive functions remain elusive. The study determined the effects of naphthoquinone on reproductive functions of Plasmodium berghei berghei-infected male Swiss mice

Methods: Thirty male Swiss mice were divided into 6 groups $(\mathrm{n}=5)$ namely; Control, $1 \mathrm{mg} / \mathrm{kg}$ naphthoquinone, $2 \mathrm{mg} / \mathrm{kg}$ naphthoquinone, Plasmodium berghei berghei (Pbb)-infected, Pbb-infected $+1 \mathrm{mg} / \mathrm{kg}$ naphthoquinone and Pbb-infected $+2 \mathrm{mg} / \mathrm{kg}$ naphthoquinone. Parasitaemia was confirmed by microscopy. Naphthoquinone (i.p.) was administered for seven days following confirmation of parasitaemia. Thereafter, they were sacrificed. Serum levels of FSH, LH, testosterone and cortisol were assayed via ELISA. Sperm characteristics were evaluated by microscopy. Data were expressed as mean \pm SEM and analysed using ANOVA at $p<0.05$.

Results: Sperm motility reduced in the Pbb-infected compared with control. Sperm viability, motility and count reduced in naphthoquinone only groups and Pbb-infected+naphthoquinone groups compared with the control. Naphthoquinone groups and Pbb-infected alone decreased in LH and testosterone concentrations compared with the control.

Conclusion: Naphthoquinone treatment impaired reproductive functions in Plasmodium berghei berghei-infected male Swiss mice.
\end{abstract}

Keywords: Naphthoquinone; Plasmodium; Male Reproductive Functions; Malaria, Sperm.

\section{Introduction}

Malaria, a devastating disease caused by plasmodium, occurs mainly in the tropical and sub-tropical regions of the world and more than 3 billion people worldwide are at risk of the disease [1]. There were 214 million clinical cases and 438,000 deaths attributable to malaria in 2015 [2]; majority of which occurred in the sub-Saharan Africa, making malaria a leading public health and economic problem in the region [1]. Malaria infection starts in the mammalian host with the injection of plasmodium sporozoites by a mosquito bite. Sporozoites, after travelling to the liver eventually develop and generate millions of merozoites that are released into the blood stream. With the infection of erythrocytes, the clinical phase of malaria begins [3].

Anti-malarial drugs are the most effective treatments against the disease. While several antimalarial drugs are available, their efficacy has been limited by rapid development of resistant strains of the parasites [4]. Resistance of malarial parasite to previous generations of medicines, such as chloroquine and sulfadoxine-pyrimethamine, became widespread in the 1950s and 1960s, leading to the introduction of artemisinin combined therapy. In recent years, parasite resistance to artemisinin has been detected in African countries [5]. An escalation of the incidence of malaria-related morbidity and mortality appears inevitable in view of the increase and world-wide spread of the drug resistant parasites [4]. The resistance of these parasites to existing drugs has necessitated the development of drugs which will be effective against all strains of the parasite [4]. Among the drugs that are being investigated are the naphthoquinones and their derivatives [6].

Naphthoqunones are isolated from the wood of trees belonging to the families Bignoniaceae and Verbenaceae and have been subjected to an interdisciplinary study since the seventies [7]. 1, 4-naphthoquinones are organic compounds which possess anti-bacterial, anti-tumor and antimalarial properties [8]. The 1, 4-naphthoquinone derivatives have shown moderate to good in vitro antimalarial activities even against plasmodium falciparum; the parasites which shows the greatest antimalarial drug resistance [6].

Rodents, like primates, are possible hosts of malaria [9]. Eleven species of plasmodium have been described in population of tree dwelling rodents which live in the central African rainforest and many of these have been widely studied as different experimental models of human malaria $[9,10]$.

It is pertinent to note that many antimalarial drugs have been implicated in male infertility. For instance, mention has been made of the apparent reduction in fertility of male rats by chloroquine [11]. This drug has been reported to completely obliterate Leydig cell response to lutropin and hormones having lutropin-like activity in vitro [12]. It also inhibits basal and stimulated testosterone secretion in decapsulated testis in vitro [13]. 
In view of the growing interest in the development of naphthoquinone into antimalarial drug, it has become imperative to investigate its possible effects on reproductive functions particularly because there is a high prevalence of male infertility in the regions where malaria is predominant [14].

\subsection{Aim and objectives}

The present study was therefore designed to investigate the effects of naphthoquinone on sperm characteristics, follicle stimulating hormone, luteinizing hormone and testosterone in Plasmodium berghei berghei ( $\mathrm{Pbb}$ )-infected Swiss mice.

\section{Methodology}

\subsection{Animal}

Thirty male Swiss mice (18-22 g) obtained from the National Veterinary Research Institute (NVRI) farms, Vom, Plateau State, Nigeria were used for the study. The research was conducted at the Central Animal House, College of Medicine, University of Ibadan. All mice were acclimatized for two weeks before the commencement of the study. The mice were all fed with pelletized rodent feed and water ad libitum.

\subsubsection{Animal grouping}

The mice were grouped into 6 groups as described below

\begin{tabular}{l}
\hline Treatment groups ( $\mathrm{n}=10$ in each group) \\
\hline Group I- Control (Distilled water) \\
Group II- $1 \mathrm{mg} / \mathrm{kg}$ naphthoquinone \\
Group II- $2 \mathrm{mg} / \mathrm{kg}$ naphthoquinone \\
Group IV- Plasmodium berghei berghei infected mice \\
Group V- Plasmodium berghei berghei infected + naphthoquinone $(1 \mathrm{mg} / \mathrm{kg})$ mice \\
Group VI- Plasmodium berghei berghei infected + naphthoquinone $(2 \mathrm{mg} / \mathrm{kg})$ mice \\
\hline
\end{tabular}

\subsection{Infection of mice with plasmodium berghei berghei}

Anka $1 \mathrm{~N}$-strain of the malarial parasite, Plasmodium berghei berghei-donor mice were obtained from the Nigerian Institute of Medical Research, Lagos, Nigeria. Each mouse was subsequently given standard intra-peritoneal inoculum of parasite-infected blood with the aid of a $1 \mathrm{~mL}$ disposable syringe. The method of blood-induced plasmodium infection in mice used in this study was first described by Peters [15] and used by others [16].

\subsection{Determination of potency and parasitaemia}

Blood samples were collected from the infected mice and thin blood smears were prepared, fixed with methanol, and stained with a 1:10 dilution of Giemsa staining 1x phosphate buffer ( $\mathrm{pH}$ 7.1). Parasites were visualized under a 100x oil immersion microscope objective lens, and parasitaemia was calculated by counting the number of parasites.

\subsection{Drug administration}

The drug naphthoquinone was weighed and dissolved in Tween 20. The drug was administered intra-peritoneally with the use of a $2 \mathrm{ml}$ syringe and needle for 7 days. Control mice received Tween 20.

\subsection{Autopsy}

The percentage parasitaemia levels and bodyweight of each mouse was determined daily. At the end of the experimental period, mice were sacrificed by cervical dislocation. Blood was collected under chloroform anaesthesia by carefully transecting the caudal vein. Microscope slides were smeared with a thin film of the blood and the percentage parasitaemia level was determined daily. The remaining blood was allowed to clot and afterwards centrifuged using $3000 \mathrm{rpm}$ for 5 minutes. The serum gotten was analysed for hormonal levels.

\subsection{Assessment of sperm motility, viability and counts}

The cauda epididymis was dissected out immediately and the epididymal volume was determined (approximately $0.01 \mathrm{~mL}$ per mouse). The testes were carefully exposed and one of them was removed together with its epididymis. The epididymis was separated and the epididymal fluid was collected from the caudal part and the progressive sperm motility, sperm count, live/dead ratio (viability) and sperm morphology were determined as described earlier [17].

\subsubsection{Sperm motility}

Sperm motility evaluation was done immediately. Two drops of epididymal fluid were placed on a microscope slide and two drops of warm $2.9 \%$ sodium citrate were added. The slide was then covered with a cover slip and examined under the microscope using $40 \times$ objectives with reduced light. 


\subsubsection{Sperm viability}

Sperm viability was done using the eosin/nigrosin stain. The dead sperm took up the stain. Sperm morphology was carried out by means of the Walls and Ewas stain.

\subsubsection{Sperm count}

Epididydmal sperm count was done by homogenizing the epididymis in $0.5 \mathrm{~mL}$ of Normal saline and count were done by using the haemocytometer method (i.e. using the improved Neubauer counting chamber).

\subsection{Immunoassay}

Serum levels of testosterone, luteinizing hormone, follicle stimulating hormone and cortisol were measured using ELISA kits (Dialab, USA).

\subsection{Statistical analysis}

Data were expressed as mean \pm SEM and analysed using ANOVA at significant level of $\mathrm{p}<0.05$.

\section{Results}

\subsection{Effects of naphthoquinone on sperm indices in mice}

Sperm motility was reduced in the Pbb-infected compared with control. Sperm viability, motility and count were reduced in naphthoquinone treated groups and Pbb-infected mice treated with naphthoquinone compared with control group. The Pbb-infected treated with naphthoquinone had greater reductions in sperm viability and motility than the Pbb-infected alone and the naphthoquinone treated alone (Table 1).

\subsection{Effects of naphthoquinone on reproductive hormones in plasmodium berghei berghei infected and uninfected mice}

The uninfected and Pbb-infected mice treated with naphthoquinone as well as the plasmodium infected alone had significant decreases $(p<0.05)$ in serum levels of luteinizing hormone and testosterone compared with control group. However, this drug as well as the parasite significantly $(\mathrm{p}<0.05)$ increased serum cortisol levels in these mice (Table 2$)$.

\section{Discussion}

Existing potent antimalarial agents have been known to exhibit antifertility effects especially in males. With the evolution of highly resistant strains of malaria parasites [18], the development of new drugs is highly pertinent. One of such drugs which has shown potent anti-malarial effect is naphthoquinone [4]. However, its effects on male reproductive functions remain elusive. Thus, the study investigated the effects of naphthoquinone on reproductive functions of pbb-infected male Swiss mice.

Naphthoquinone was observed to suppress reproductive functions as demonstrated by reductions in sperm indices, luteinizing hormone and testosterone in the groups treated by naphthoquinone. These results corroborate earlier findings in which lapachol- a naphthoquinone extracted from plants of the genus Tabebuia adversely affected the seminal vesicle [19]. Furthermore, the marked impairment of sperm motility, viability and count showed a dose dependent effect on these parameters.

The marked reduction in sperm viability, motility and count may be related to its anti-proliferative property. According to Dinnen and Ebisuzaki, [20], naphthoquinone is an anti-proliferative agent and the mechanism of its antimitotic effect is due to mitochondrial and phosphorylation inhibition [21]. Others have suggested the involvement of reactive oxygen species [22]. Significantly, Uematsu suggests that naphthoquinone's action is not mediated via the hypophysis [23].

Naphthoquinone also caused reduction in serum testosterone and luteinizing hormone in this study. Testosterone is secreted by the Leydig cell under the stimulation of luteinizing hormone. As such, a reduction in the secretion of luteinizing hormone by the anterior pituitary causes a reduction in testosterone secretion. Testosterone reduction in this study seems to be caused by decreased luteinizing hormone level and since spermatogenesis is dependent on testosterone [24], the reduced testosterone therefore suppressed spermatogenesis. The reduced luteinizing hormone concentration also suggests that naphthoquinone affects the functions of anterior pituitary gland.

There was also an increase in cortisol concentration in all groups that had reduced testosterone. This suggests the involvement of the 'pregnenolone steal' phenomenon in which more pregnenolone is diverted away from testosterone pathway and channeled into the production of cortisol in the steroidogenic pathway [25].

It is also worthy of note that reproductive functions were impaired in the group that was infected with plasmodium berghei berghei, only, however, treatment with naphthoquinone aggravated reproductive dysfunction in the plasmodium infected group.

\section{Conclusion}

Malaria infection affected reproductive functions in plasmodium berghei berghei-infected male Swiss mice, however, treatment with naphthoquinone further deteriorated reproductive functions in these mice.

Authors declare no conflict of interest 
Table 1: Sperm Viability, Sperm Motility and Sperm Count in Plasmodium Berghei Berghei-Infected and Naphthoquinone Treated Male Mice

\begin{tabular}{llll}
\hline Hormones & Sperm viability $(\%)$ & Sperm motility $(\%)$ & Sperm count (million/mL) \\
\hline Control & $88.33 \pm 4.73$ & $70.33 \pm 1.53$ & $20.75 \pm 2.46$ \\
$1 \mathrm{mg} / \mathrm{kg}$ naphthoquinone & $79.00 \pm 3.00^{*}$ & $57.67 \pm 6.81^{*}$ & $13.17 \pm 1.01^{*}$ \\
$2 \mathrm{mg} / \mathrm{kg}$ naphthoquinone & $63.00 \pm 2.65^{*}$ & $41.33 \pm 8.33^{*}$ & $9.42 \pm 3.01^{*}$ \\
Pbb-infected & $84.23 \pm 3.02$ & $53.06 \pm 2.05^{*}$ & $20.07 \pm 2.32$ \\
Pbb-infected + 1 mg/kg naphthoquinone & $62.30 \pm 2.75^{*}$ & $39.53 \pm 8.43^{*}$ & $13.13 \pm 1.02^{*}$ \\
Pbb-infected + 2 mg/kg naphthoquinone & $61.02 \pm 2.60^{*}$ & $21.33 \pm 6.33^{*}$ & $12.17 \pm 1.03^{*}$ \\
\hline
\end{tabular}

Values are expressed as mean \pm SEM; $* \mathrm{P}<0.05$ compared with control; $\mathrm{n}=5$.

Table 2: Serum Luteinizing Hormone, Prolactin, Follicle Stimulating Hormone and Testosterone Levels in Plasmodium Berghei Berghei-Infected and Naphthoquinone Treated Male Mice

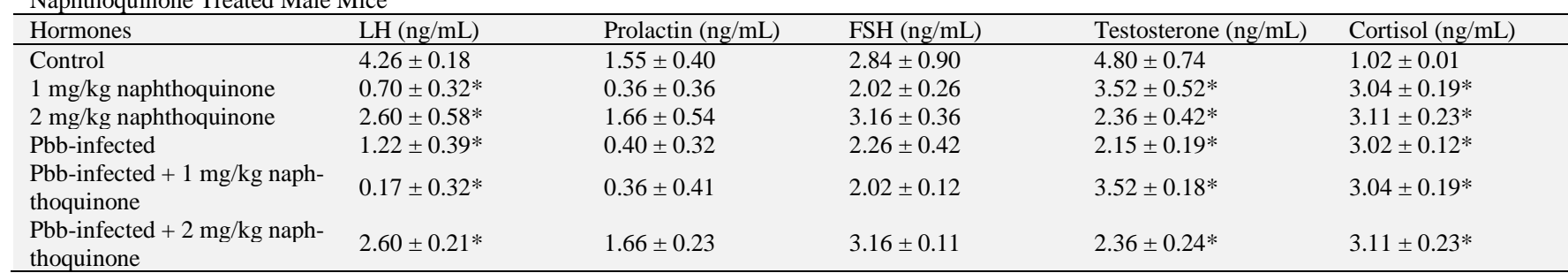

Values are expressed as mean \pm SEM; $* \mathrm{P}<0.05$ compared with control; $\mathrm{n}=5$.

\section{References}

[1] N. Scott, S.A. Hussain, R. Martin-Hughes, F.J.I. Fowkes, C.C. Kerr, R. Pearson, D.J. Kedziora, M. Killedar R.M. Stuart, D.P. Wilson. Maximizing the impact of malaria funding through allocative efficiency: using the right interventions in the right locations, Malaria Journal 16 (2017) 368 https://doi.org/10.1186/s12936-017-2019-1.

[2] World Health Organisation. World malaria report. Geneva: World Health Organization; 2015.

[3] M. Cunha-Rodrigues, S. Portugal, M. Febbraio, M.M. Mota. Infection by and protective immune responses against Plasmodium berghei ANKA are not affected in macrophage scavenger receptors A deficient mice. BMC Microbiology 6 (2006) 73. https://doi.org/10.1186/1471-2180-6-73.

[4] G. Kokwaro. Ongoing challenges in the management of malaria. Malaria Journal 8 (2009) S2. https://doi.org/10.1186/1475-2875-8-S1-S2.

[5] R. Lu, Culletin, M. Zhang, A. Ramaprasad, L. von Seidlein Emergence of Indigenous Artemisinin-Resistant Plasmodium falciparum in Africa. The New England Journal of Medicine 376 (2017) 991-993. https://doi.org/10.1056/NEJMc1612765.

[6] A. Sharma, I.O. Santos, P. Gaur, V.F. Ferreira, C.R. Garcia, D.R. Rocha. Addition of thiols to o-quinone methide: new 2-hydroxy- 3phenylsulfanylmethyl [1], [4] naphthoquinones and their activity against the human malaria parasite Plasmodium falciparum (3D7). European Journal of Medicinal Chemistry 59 (2013) 48-53. https://doi.org/10.1016/j.ejmech.2012.10.052.

[7] C.G. De Mouraa, F.S. Emerya, C. Neves-Pintoa, M.F.R. Pintoa, A.P. Dantasb, K. Salomão, S.L. de Castrob, A.V. Pintoa. Trypanocidal Activity of Isolated Naphthoquinones from Tabebuia and Some Heterocyclic Derivatives: A Review from an Interdisciplinary Study. The Journal of the Brazilian Chemical Society 12, (2001) 325-338. https://doi.org/10.1590/S0103-50532001000300003.

[8] W. Qian, H. Shich Naphthoquinone-induced cataract mice possible involvement of $\mathrm{Ca}^{2+}$ Dieased calpain activation. Journal of Ocular Pharmacology and Therapeutics 17 (2001) 383-92. https://doi.org/10.1089/108076801753162799.

[9] F.E.G. Cox. Major models in malaria research: rodent. In Malaria: principles and practice of malariology (ed. W. H. Wernsdorfer \& I. McGregor), 1988; 1503-1543.

[10] I. Landau, P. Gautret. Malaria: Parasite Biology, Pathogenesis and Protection, edited by I. W. Sherman. Washington DC: American Society for Microbiology. 1998; 401-417.

[11] A.I. Vawva, G. Saade. Effects of chloroquine on male infertility in wistar rats. Suid Afr. Lydskrit Wetenskap, 83(1987) 489-491.

[12] M.R. Sairam. Drug Effects on Lutropin Action. In: Structure and Function of Gonadotrophins, McKerns, K.W. (Ed.). Plenum, New York, (1978) 274-294. https://doi.org/10.1007/978-1-4684-3414-9_12.

[13] E.U. Nduka. Inhibition of testosterone secretion in the rat testes by chloroquine. IRCS. Journal of Medical Science 14 (1986) $14: 1185$.

[14] A. Agarwal, A. Mulgund, A. Hamada, M.R. Chyatte. A unique view on male infertility around the globe. Reproductive Biology and Endocrinology 13 (2015) 37. https://doi.org/10.1186/s12958-015-0032-1.

[15] W. Peters. Rational methods in the search for antimalarial drugs. Trans Roy Soc Trop Med Hyg 61 (1967) 400-410. https://doi.org/10.1016/00359203(67)90015-6.

[16] J.M. Makinde, P.O. Obih Screening of Morinda lucida leaf extract for antimalaria action on Plasmodium berghei berghei berghei in mice. African Journal of Medicine and Medical Sciences 14 (1985) 59-63.

[17] A.T. Farag, M.H. Eweidah, A.M. El-Okazy. Reproductive toxicology of acephate in male mice. Reproductive Toxicology 14 (2000) 457-62. https://doi.org/10.1016/S0890-6238(00)00094-0.

[18] J.F. Trape, G. Pison, M.P. Preciosi, C. Enel, Desgrees du Delaunagv, B. Samb, F. Simondon. Impact of chloroquine resistance on malaria mortality Comptes Rendus de l'Académie des Sciences 3 (1998) 689-697. https://doi.org/10.1016/S0764-4469(98)80009-7.

[19] Rita de Cassia da Silveira esa, Martha de Oliveira Guerra Reproductive toxicity of Lapachol in Ault Male wistar rats submitted to short-term treatment. Department de Biologica Universidade Federal de juiz de Fora, MG Brasil. 2007.

[20] R.D. Dinnen, K. Ebisuzaki. The search for novel anticancer agents: A differentiation-based assay and analysis of folklore product. Anticancer Research 17 (1997) 1027-1033.

[21] C.F. Santana, O.G. Lima, I.L. Dalbuqurque, A.L. Lacerda, D.G. Martins. Observacoes sobre as propriedades antitunorais e toxicotogicas do extrato do liber e de alguns componentes do cerne do pau dorco. Rev. Inst. Antibiot. 8 (1968) 89-94.

[22] M.R. Kumar, K. Aithal, B.N. Rao, N. Udupa, B.S. Rao. Cytotoxic, genotoxic and oxidative stress induced by 1,4-naphthoquinone in B16F1 melanoma tumor cells. Toxicology in Vitro. 23 (2009) 242-50. https://doi.org/10.1016/j.tiv.2008.12.004.

[23] K. Uematsu. Testicular changes of rats induced by nitrofurazone. A light and electron microscopic study. Medical Journal of Osaka University 16 (1966) 287-320.

[24] W.H. Walker, "Non-Classical Actions of Testosterone and Spermatogenesis." Philosophical transactions of the Royal Society of London. Series B, Biological sciences RoyalSociety (Great Britain) 365.1546 (2010) 1557-1569.

[25] C. Wellwood, R. Sean. "Adrenal and Thyroid Supplementation Outperforms Nutritional Supplementation and Medications for Autoimmune Thyroiditis.” Integrative Medicine: A Clinician's Journal 13.3 (2014): 41-47. Print. 